\title{
FEMSLASH FANFICTION AND LESBIANISM: EFFORTS TO EMPOWER AND EXPRESS ASIAN AMERICAN WOMAN SEXUALITY
}

\author{
Tyas Willy Kartika \\ e-mail: kartika.tw@mail.ugm.ac.id \\ Maria Elfrieda C.S.T \\ e-mail: mariaelfriedacst@gmail.com
}

\begin{abstract}
The existence of fan fiction nowadays shows more progressive development especially in this digital era when people does not only use internet for communicating and socializing across time and space but they also show their creativity, one of them is by writing a fan fiction. By writing fan fiction in online platforms, people get the opportunity to express their interests and their identities. This opportunity is also obtained by minority groups such as LGBTQ+ where they can express their identity through fan fiction. LGBTQ+ community utilizes online platform as the tool that brings benefit for them. In this case, writing fan fiction in online platforms allows people to create the preferable representation of minority groups and empower them as the part of LGBTQ+ community. This phenomenon can be seen through a website named Asianfanfics.com which shows an increasing number of fan fictions especially the ones with lesbian related tags such as girl $\mathrm{x}$ girl, lesbian, and femslash. Particularly, through the femslash subgenre, people use fan fiction to question the heteronormativity. Regarding to this phenomenon, an interview was conducted by choosing three Asian American fan fiction writers from Asianfanfics.com as the interviewees. Furthermore, by using gender theory and intersectionality, this article focuses on how fan fiction becomes a safe space to express their sexual identities and how lesbian relationship is viewed by Asian families.
\end{abstract}

Keywords: Asian American; empowerment; fan fiction; femslash; $L G B T Q+$; sexuality; women

DOI $\quad$ : https://doi.org/10.22146/rubikon.v8i2.69689

Available at https://jurnal.ugm.ac.id/rubikon/article/view/69689

This work is licensed under a Creative Commons Attribution-ShareAlike 4.0 International License

\section{INTRODUCTION}

The rapid development of the technology especially internet helps to increase the life quality of human, it is also believed
Article information

Received: 12 August, 2021

Revised: 26 August, 2021

Accepted: 09 September, 2021 creating major shifting of the way people treat minority groups, including LGBTQ+ people. In this era of new media, LGBTQ+ culture has been spread globally 
(Mokhtar, Sukeri, \& Latiff, 2019). Janczak (2017) stated that stated that one of the most beneficial contributions of social media is bringing positive impact on marginalized groups like the LGBTQ+ community. With the rise of social media, the LGBTQ+ community was able to find different ways to use this as a platform or place to express themselves. Research has also investigated how sexual minorities use social media to portray and develop their personal identities online (Alfasi, 2019; Brandes \& Levin, 2014; Duguay, 2016; Fox \& Ralston, 2016; Hillier \& Harrison, 2007; \& Vogel, Rose, Roberts, \& Eckles, 2014a, b). To be able to express and portray their identities online, they utilize internet and social media. Within social media, there are various widely known platforms to share ideas like social networking sites, review sites, video hosting sites and community blog / blogging platforms (writing sites). This research focuses on the use of fan fiction sites in expressing sexual identity.

Fan fiction serves many functions. Klink (2017) argued fan fiction allowed fans to create better representation of minority groups, or that it is a rebellion against the entertainment industry. We have mixed feelings about this argument: fan fiction isn't always unwelcome to the entertainment industry, and it definitely hasn't been equally kind to all underrepresented minorities. Thus, the cyberspace is believed to be a safe space to express the minority groups' sexual identity. Janczak (2017) stated that one of the most beneficial contributions of social media is bringing positive impact on marginalized groups like the LGBTQ+ community. With the rise of social media, the LGBTQ+ community was able to find different ways to use this as a platform or place to express themselves. Research has also investigated how sexual minorities use social media to portray and develop their personal identities online (Alfasi, 2019; Brandes \& Levin, 2014; Duguay, 2016; Fox \& Ralston, 2016; Hillier \& Harrison, 2007; \& Vogel, Rose, Roberts, \& Eckles, 2014a, b). Social media provided chance to connect with people who have had the same experiences; it showed how vast and varied the community was. Social media within this context takes a role in accommodating particular community and being a safe sphere for the LGBTQ+ community, but it also has had a positive contribution on the culture. This article tries to answer how fan fiction becomes a tool to express the sexual identity of minority group (woman), especially lesbian and challenging the heteronormativity that applies in society. Gender theory and intersectionality were employed to make sense the depiction of lesbianism within fan fiction works on fan fiction writing site: Asianfanfics.com.

To do the analysis, this research is using qualitative method. Based on Creswell (2014), qualitative methods rely on text and image data, have unique steps in data analysis, and refer to diverse designs. Three fan fiction (fem slash fan fictions) writers that are interviewed, JN, DK and TS. They have shown significant involvement with the fem slash writing activities in connection to their sexuality and their being as Asian descendants who live in the US. Following Miles, Huberman \& Saldana (2014), the data analysis process is divided into 3 main steps namely data condensation, data display and conclusion drawing. Data analysis procedure that is done within this research is started with creating a condensed data by selecting, focusing, simplifying, abstracting, and/or transforming the data that appear in the interviews. Data 
display within this research is presented in form of detailed explanation of the condensed data to lead the conclusion.

\section{DISCUSSION}

\section{The Struggle against Heteronormativity: The Asian American LGBTQ+ Movement}

Nowadays, when talking about the expression of sexuality, the LGBTQ+ community tends to be more vocal and open about their sexual identity. Since the emergence of LGBTQ+ rights movement, the legalization of same-sex marriage, and the expression of sexual freedom in popular culture, it seems that the talk on sexuality is no longer being a taboo thing. However, it is still undeniably true that the struggle on expressing ones sexuality still exists. In fact, seeing how media tries to portray LGBTQ+ does not only show the attempts on the normalization of sexual freedom itself but also indicates the never ending struggle going on in the society especially for LGBTQ+ community in order to fight for their rights against the social discrimination.

The discussion on the social discrimination towards LGBTQ+ community leads to the social belief on heteronormativity. Heteronormativity itself refers to the belief on heterosexuality especially on gender binary associated natural roles and how people match their assigned sex (van der Toorn et al., p. 160). Basically, heteronormativity rules the whole gender relation which is also the result of the patriarchal system in a society. In this case, it is believed to be natural when men and women always stick to their gender roles. As a matter of fact, this patriarchal system then triggered the reaction especially from women which resulted in the emergence of Feminist movement since the nineteenth century.
Initially, the emergence of Feminist movement focused on women's equal rights in every social aspect. This movement is the response toward the male domination in the society and the discrimination experienced by women. Furthermore, this movement is gradually seen as human rights movement which gets further response from other community including LGBTQ+ community.

Back to the idea of heteronormativity, Feminism and LGBTQ+ movement criticize the inequality between men and women. Similar to Feminist movement, LGBTQ+ rights movement criticizes the discrimination towards LGBTQ+ community which comes in a form of homophobic and trans phobic attitude from the mainstream. In an article on the relation between Feminism and LGBTQ+, it is stated that:

the basis for homophobic and trans phobic attitudes is the inequality between men and women. In our society, men and women are still depicted as Venus and Mars, black and white, two polar opposites that may complement one another but are not equal (Kushnarenko, 2019).

From this statement, it can be understood how the inequality between men and women leads to the discrimination towards LGBTQ+ movement which is seen as the deviation from the heteronormativity itself. In this case, not only rules the supposedly normal roles for men and women in a society, heteronormativity also emphasizes the idea of opposite sexual attraction between men and women. According to heteronormativity, it is only normal when men and women are attracted to the opposite gender and this idea puts the LGBTQ+ people in the abnormal side which somehow justifies the rejection and discrimination towards LGBTQ+ community. 
Even before claiming the label as LGBTQ+ community, the word "queer" was taken as the umbrella term which is used to be an insult for non-heteronormative individuals that later on became popular because it underlines the fluidity of gender and sexuality (Los Angeles Conservancy, 2020). Related to this, a feminist psychologist named Lisa Diamond explains that:

people can be sexually fluid; at some point in your life, you could feel completely straight, while at other times, you might feel attracted to the same-sex. Demeaning terms are harmful and make you feel like you were doing something abnormal. It's OK for our identities to be in flux; not everyone has an identity that remains the same (Cochrane, 2016).

In this case, there is an ongoing debate on sexual identity especially when it comes to the existence of LGBTQ+ community against the heteronormativity which once again also emphasizes the ongoing struggle for the LGBTQ+ individuals. They have to live with fear of doing something wrong or being accused as abnormal individuals among the society. This is also the reason behind the hesitation of coming out as a homosexual even to their family and the uncertainty of whether they would be accepted by the society or not.

Despite of the struggle and the obstacle that they have to overcome, the LGBTQ+ community keeps fighting for their rights and this fight has been going on for decades. Since 1900s until now, there are some monumental events which mark the LGBTQ+ civil rights movement particularly in America. The establishment of gay rights groups such as the Society for Human Rights in 1924 and the Mattachine Society in 1950 with its 1966 'Sipin' protest in New York City, also the 1969 act of confrontations called Stonewall riots or
Stonewall uprising commemorate the beginning of LGBTQ+ civil rights movement in the United States (Webster, 2019). Since then, the LGBTQ+ community together with contemporary feminist and anti-racist movements seeks for social transformation.

Around 1970s-'80s, two remarkable figures named Marsha P. Johnson and Sylvia Rivera advocated the discriminated LGBTQ+ individuals, established the Street Transvestite Action Revolutionaries for homeless LGBTQ+ youth and sex workers, marched and lobbied for the rights of HIV-positive people through ACT UP organization, also opposed the exclusion of transgenders from New York's 2002 Sexual Orientation Non-Discrimination Act (Li, 2021).

These figures are only two examples among so many figures that fight for the LGBTQ+ civil rights. Finally, they make a groundbreaking achievement for LGBTQ+ rights and civil rights law with the legalization of same-sex marriage since 2003 after activists, celebrities, and public relations campaigns swayed public opinion toward LGBTQ+ community. But, not stopping there, the movement still marching on especially on the attempt to oppose the heteronormativity and to find justice, equality, and dignity for LGBTQ+ community in the society.

It is clear enough that one of the main goals of the LGBTQ+ movement is to normalizing the homosexuality as a part of sexual freedom. Opposing the heteronormativity, the LGBTQ+ movement attempts to change the label of 'abnormal' from the LGBTQ+ individuals. However, when talking about the normalization of homosexuality or same-sex relationship, there is an idea that the homosexuality has never been 'abnormal' in the first place. In an article 
on the normalization of LGBTQ+, it is stated that:

in other times and places, humans understood much better than today that sexual attraction and gender expression are varied and often fluid. [...] Sexual practices are almost always highly regulated in any given culture. It's often been the case, however, that cultures have existed in which people understood quite well that same-sex attraction was a normal part of the human experience (Finn, 2019).

Through this article, it can be understood how heteronormativity is seen as the act of denormalization of homosexuality. It is assumed that the change of perspective on seeing the sexual attraction and gender expression happened as the result of Western colonization and the spread of Christianity. It is known that the impact of the colonization and Christianity was very strong and attached to other cultures to the point where they actually adopt the same ideas on seeing things including seeing the sexual attraction and gender expression based on heteronormativity.

However, some cultures historically believed on the fluidity of gender expression. Among all ethnics around the world, Asians are the ethnic group with their own history on homosexuality. Asian countries such as Japan, China, and India even have their own historical traces on homosexuality. In details, Wong explains that:

the Kama Sutra has a chapter of explicit instructions on gay sex. In imperial China, many Han dynasty rulers were bisexual or homosexual. Scholars Bret Hinsch and $\mathrm{Li}$ Yinhe note that tales of homoerotic relationships, such as those of Long Yang and Emperor Ai of Han, were widely known and valorized throughout Chinese history. Lesbian and gay partnerships were meanwhile ubiquitous throughout the Ashikaga and Edo era Japan, even under the most repressive, feudalistic rule of its political history.

However, when we reflect to the current situation, the issue of homosexuality in Asian countries is still on a debate. In Japan, for example, even though there are no laws in prohibiting the discrimination based on gender expression, there is a progress on several aspects such as politic, education, health, and employment which shows recognition of same-sex partnership and fulfills their rights as citizens. Meanwhile, in China, the government even strictly bans the LGBTQ+-related contents on social media under the pretext of "clean cyberspace" and shows more control over the LGBTQ+ community (Chen, 2018). It can be perceived how heteronormativity is deeply rooted in the current society. No matter how hard they try, the LGBTQ+ individuals keep finding difficulties, obstacles, and discriminations. The fact that they have cultural knowledge on the fluidity of gender expression does not even affect the current belief on heteronormativity. As a matter of fact, the LGBTQ+ community has to start fighting all over again for something that actually has never been believed as "abnormal" in the first place and the progress on recognizing the same-sex relationship is not the result of looking back at the cultural knowledge itself but because of the current movement from LGBTQ+ community.

Put it into American context, Asian Americans are also the ones who voice out the LGBTQ+ rights. Even before the Stonewall riots and other LGBTQ+ movements, the queer Asian Americans already participated in Civil Rights movement, anti-war movement, women's and earlier gay liberation movements. However, being one of the ethnic 
minorities in America doubles up the struggle for queer Asian Americans. During that time, the LGBTQ+ community was dominated by white Americans. There was no community established for queer Asian Americans because not many Asians reveal their sexual identity due to the anti-racism movement during that time. In an article, a journalist and an activist named Daniel C. Tsang (2006) shares his experience as the part of queer Asian American movement and writes:

although I was active in both Asian and in gay groups, I had a sense of isolation since the gay group was largely white, and there was practically no other gay Asian with whom I could identify, except for the official "gay advocate" at the university, Jim Toy. He was hired by the university to serve gay students, but he was not widely known as Asian and certainly wasn't active in the Asian American Movement that had emerged by then (227).

Through this, it can be understood how queer Asian Americans had to go through alienation. Some of them even have to either hide their sexual identity or not to be associated in Asian American movement because the combination of these two identities was not conceivable for many people at that time.

However, just like other LGBTQ+ community, queer Asian Americans keep expressing their rights against heteronormativity. Not only through rally, demonstration, or riots, they find their way through various media. Around 1980s and 1990s, newspaper, magazine, and literature were the media for queer Asian Americans to express their sexuality. In an article on the history of queer Asian American activism, Amy Sueyoshi (2016) mentions some examples such as:
Phoenix Rising as first Asian American lesbian newsletter, [..] Kitty Tsui with her poetry and the book The Words of a Woman Who Breathes Fire as the first book from Chinese American lesbian, [...] single-authored books from lesbians poets and writers including Merle Woo and Chea Villanueva, [...] the portrait of Kitty Tsui in lesbian erotica magazine On Our Backs in 1988 and 1990, as well as in New York City's Village Voice as first Asian lesbian to appear on the cover, also [...] her book titled Breathless in 1995 with intense scenes of pleasure, pain, and Chinese food, which won the Firecracker Alternative Book Award (2022).

Those are the few examples of the way queer Asian Americans express their sexuality despite of the rejection and discrimination towards them. Not only that, these works also gain attention from other LGBTQ+ community especially the white activists on seeing queer Asian Americans as the part of LGBTQ+ movement itself. Up to this point, it can be seen that the LGBTQ+ movement does not stop on demonstrations but they also spread the movement to mass media. Nowadays, we can see how the media such as television, newspaper, magazine, film, and literature portray the LGBTQ+ community which makes their existence even stronger than before.

Among those mass media, literature might be the most preferable media for LGBTQ+ movement. Through the previous examples, the LGBTQ+ individuals even started to publicly show their sexual identity through their own literary works. Just like starting a demonstration, writing their own story as the LGBTQ+ individuals is a step they can take to proclaim their existence. As if to say that when other mass media ignore their existence, then it is better for them to pave 
their own way. Names like Misa Sugiura, Franny Choi, Aminah Mae Safi, Esmé Weijun Wang, Hieu Minh Nguyen, Yanyi, Rahul Mehta, Ryka Aoki, and many others are contemporary Asian American writers who enliven the queer literature. Most of them present stories on the self-discovery, struggles and discriminations experienced by LGBTQ+ individuals. Their stories can also be the media for them to share the similar experiences with the readers especially the LGBTQ+ ones. Moreover, with the increasing number of queer writers, the increasing number of literary works written, and the increasing interest from the readers, that's where the LGBTQ+ community gains recognition from the society even though they are still classified as a minority group. The same thing happened with the portrayal of LGBTQ+ community through other mass media. So, the more mass media portray the LGBTQ+ community, the bigger the chance for them to be recognized by the society and slightly shift the belief on heteronormativity.

Unfortunately, when talking about queer Asian Americans on mass media, it is undeniably true that they get lesser chance than the others. When it comes to stories about Asian Americans, the heteronormativity is still very domineering. For example, in an article on Asian American LGBTQ+ stories in Hollywood, Lakshmi Gandhi (2021) explains that:

another recent study on Asian American representation in Hollywood found that only 3.4 percent of Hollywood's topgrossing movies featured Asian American or Pacific Islander leads and that none of the films studied featured an LGBTQ Asian American or Pacific Islander lead. That number is an indication of how hard it is to get producers and studios to invest in stories about queer Asian Americans in particular.

By reading statements above, it is reaffirmed how Asian Americans are still struggling to find their place in mass media and it is even harder for the queer ones to even show their existence. This problem still arises in connection with the previously mentioned issue of being identified as Asian Americans as well as queers which also triggers overly complex issues of race, gender, and sexuality. It also means that queer Asian Americans in particular will feel totally unrepresented and it will be more difficult for them to socially express their sexual identity compared to the others.

However, back to the use of literature as the media for queer Asian Americans to express their sexual identity against heteronormativity, there is a particular type of literature especially for audiences or readers who are not only identify themselves as queers but also the ones who accept and understand the idea of same sex relationship. It is understandable that not everybody has the opportunity to find a publisher and actually publish their own literary works like the previous queer writers mentioned above. But, there is a form of literature called fan fiction which can be another alternative media for them to express their experience and understanding on homosexuality. Derived from its name, fan fiction is a literature written by fans as a creative response towards existing popular culture. According to Francesca Coppa (2017), fan fiction is defined as:

creative material featuring characters [from] works whose copyright is held by others [and] a kind of safety valve: a substitute for desires that could not be articulated, much less acted out, in our real world. 
Through fan fiction, anyone can create a whole new story using the existing works and being creative by shifting the plot lines, specifying the characterization, even creating a new universe for the story. When it comes to LGBTQ+ individuals, fan fiction can be the place for them to express their sexual identity. For those who experience the alienation and discrimination, especially queer Asian Americans, can write down their thoughts and express their desires without worrying about being judged by the society. When all mass media out there is still dominated by heteronormativity, they can turn into fan fiction and create their own world. In creating a fan fiction the LGBTQ+ individuals are not bound by any rules including heteronormativity. Besides being creative and imaginative, through fan fiction, the LGBTQ+ individuals get together as a community where they can share their experience and interest on same sex relationship.

In a study titled Fan Fiction and Fan Communities in the Age of the Internet (2006), Karen Hellekson and Kristina Busse state that "fan fiction is primarily written by women, of all ages and sexual identities, and tends to explore - or 'ship' - intimate and romantic relationships between characters." It is common knowledge how difficult it is for women to freely express themselves including expressing their thoughts about sexuality. Particularly, the Asian Americans, who are still struggling with their cultural identity as Asian women, need a media like fan fiction to express themselves and free from the patriarchal culture. In this case, even though they live in the United States where women nowadays can socially express themselves, the Asian American women do not get the same opportunity compared to women from other ethnics. The chance is even smaller for the
Asian American lesbians. Bound by the strong patriarchal culture and the heteronormativity, Asian American lesbians have to hide their sexual identity even from their family. As the ones who experience sexual discrimination, Asian American lesbians can use fan fiction to express their sexual identity and desire. Moreover, among many genres of fan fiction, there is one particular genre called femslash which specializes on girl $\mathrm{x}$ girl relationship. Not only be able to express their sexual identity, Asian American lesbians are able to oppose the heteronormativity especially when the other media does not pay much attention on represent the Asian American lesbians. Therefore, in the next sub chapter, we will discuss further about femslash as the safe place for the Asian American lesbians to express their sexual identity against heteronormativity.

\section{Fem Slash Fan Fiction as The Safe Space For Lesbians To Express Their Sexuality}

In the fan fiction, there is a subgenre known as fem slash. Typically, characters featured in fem slash are heterosexual in the canon (reality) universe. According to Oxford Lexico Dictionary (2021), fem slash is defined as a genre of fiction, chiefly published online, in which female characters who appear together in film, television, or other popular media are portrayed as having a sexual relationship. Similarly, Cambridge Online Dictionary (2021) also defines also defines fem slash as a genre of fan fiction or work written about TV, film, or book characters by their fans) in which two female characters are imagined to have a sexual relationship. In slash fan fiction, women authors question and defy the heteronormative structure of the source text, pairing up male characters who have no 
change of becoming partners in Canon. More importantly, slash authors often do this in spite of the original copyright owners, who deny any possibility of homoerotic developments in the source text (Kustritz, 2003).

In relation to women sexuality's expression, the fan fiction writing (especially slash fan fiction/ fem slash fiction) is near to the explicit sexual content. Thus, it leads to the debate related to pornography issue. As we all know, that explicit sexual content is commonly stigmatized and misunderstood as porn content. Writing works like fem slash fan fiction is not a porn action. To avoid the debate and misunderstanding in, some academics and activists distinguish between 'pornography' as exploitative material and 'erotica' as empowering (Wilson-Kovacs, 2009). Schorn (2012) identifies a latest rise in commercial feminist and queer porn explicitly framed by its maker as an act of resistance opposing exploitative mainstream pornography.

Historically, pornography was seen as violence against women, and gave rise to various anti-pornography movements initiated by feminists in 1970s. Pornography is considered to be an industry devoted to heterosexual men and to use women as sex objects. Pornography has placed women only as objects for men to enjoy, as if women are not human beings or sexual beings. Because of this anti-pornography movement, a term called erotica emerged. Erotica is used to refer to works that are sexually explicit but there is no violence against women in the work thus, the word 'erotica' then began to be used to distinguish sexually explicit work from pornography (Tyas, 2019).
Another issue comes for being a part of the LGBTQ+ community with the Asian social background. Homosexuality is still illegal in some countries where same-sex intercourse can be punished by fines, caning or prison sentences (Choy, 2019). Even as LGBTQ+ rights are increasingly recognized in the region, the community still faces discrimination and stigma in societies that promote traditional and conservative family values. Furthermore, related to the gender and sexuality issue, Friedman (2007) states although lesbians have achieved greater visibility and, in some countries, increased equality, they are routinely discriminated. This discrimination all too often takes the form of social denigration and physical violence. The shape of social denigration and physical violence could be seen in form of experiencing forced institutionalization in mental rehabilitation clinics, electro shock treatment as aversion therapy, sexual harassment in school and at work, threats of rape to make you straight, school expulsions, eviction by landlords, police kidnapping, family violence, and media stigmatization.

Lesbians face discrimination in the workplace because of their gender and their sexual orientation. Employment and job promotions are denied if women look too masculine. Male coworkers stalk and sexually harass lesbians who are unable to report for fear of backlash and retaliation. Furthermore, LGBTQ+ people in Asia (including lesbians) face violence in the "private" space-by members of core and extended family, community, and religious groups (Commission, Violence On The Basis of SOGI Against Non Heteronormative Women in Asia, 2010). This violence includes beatings, home confinement, ostracism, mental and psychological abuse, verbal abuse, forced 
marriage, corrective rape and in some cases killings to bring back family pride and honor. The fear of family and community violence is often worsened by police involvement, it could be seen on event when police officers join forces with family members to break up lesbian couples by arresting, detaining and intimidating them. In some cases, charges of kidnapping, trafficking or child abuse are brought against one of the partners. Police officers also charge lesbians under sodomy laws even if the law does not explicitly include lesbianism.

Compounding the situation is the state's lack of due diligence in applying existing laws that penalize domestic violence and sexual violence to LGBTQ+ people who are victimized, thus denying them access to complaint mechanisms and opportunities for redress. Victims do not hope to these rules for protection because they experience duality lives, and exposing the violence invites disagreement, refusal, discrimination and other shape of violence. Such a vicious cycle allows violence to stay unknown, undetected, and unchecked. In some instances, media does report on suicide pacts or foiled same sex marriages, but the coverage does not name what happened as abuse or suppression of rights. Instead, the media publicity support the stigma against LGBTQ+ people and makes them the object of ridicule and shame.

Within Asian-American Lesbians itself, similar phenomena also happened. For many Asian Americans and their families, navigating the intersection between the two identities can become a balancing act between finding strength in their lived experiences and family tradition and managing the burdens that can arise from an emphasis on putting family above the individual is the constant challenge they face although the acceptance for LGBTQ+ people in the US is better than other regions (Truong 2019).

The discrimination that is experienced by lesbians becomes multiple when they are experiencing the intersectionality. Being woman with various attributes of minority makes woman experiences intersectional discrimination (Smith, 2016). To begin with, the study of intersectionality is complex. It starts with an understanding that each subject has multiple identifiers (such as race, religion, sex, class, and any other social marker) and that these shape the various ways in which subjects make sense of their surroundings and live their lives. Intersectionality has been used to explain both individual- and group-level social phenomena (Jr, 2006).

Experiencing intersectionality is bringing a greater challenge for lesbians themselves, especially when we are living in the patriarchal society. The discrimination of being lesbians with intersectionality is inevitable. Lesbians of color face a society brimming with unjust prejudice related to their racial, gender and sexual statuses (Bridges, Selvidge, \& Matthews, 2003). It is happened because the concept of heteronormativity is constructed by patriarchy. Lesbians have worked tirelessly toward achieving legitimacy as human beings, as women, as mothers, and as life partners in the eyes of an obstinate heteronormative majority. Lesbians have felt the pain of being judged as less than human and being deemed unworthy of basic human rights. Lesbians know the pain of discrimination in key areas such as employment, housing, and healthcare. Lesbians have shed tears at vigils for hospitalized or deceased sisters that were victims of violence and hate crimes (Aragon, 
2006). Furthermore, women in homosexual relationships may not be treated equally as gay men, but this is usually only when they present themselves as femme (or traditionally feminine in appearance). For femme women in lesbian relationships, the blend of homophobia and misogyny they are subjected to is often based on men believing that the relationship exists for their sexual gratification (Williamson, 2015). Another challenge that is experienced by women and lesbians is being objectified. Women are heavily sexualized in media, and lesbian women experience this equally, and sometimes at greater rates, than heterosexual women (Tebbe, Moradi, Connelly, Lenzen, \& Flores., 2018).

A similar challenge also experienced by women and lesbian in cyberspace. Cyberspace tends to take a developing part of the social realities of many people today. Cyberspace, until now, has not managed to neutralize gender: on the contrary, it appears to be organized by the patriarchal forms, which exist in Real Life (RL) (Boudourides \& Drakou, 2000). Hence it causes to consistently produce the gender norms in cyberspace that also applied in offline sphere. When women are transferred in cyberspace, they become a site for the imagination of virtual men who play through the fantasies of embodied men (Boudourides \& Drakou, 2000). This could be because lesbians experience a more diverse set of objectification tactics than heterosexual women (Kozee. \& Tylka, 2006). Lesbian relationships have become increasingly co modified, exploited, and hyper sexualized by popular media, most often targeting male consumers' ideals of being sexually involved with two (or more) women at one time (Szymanski, Moffitt, \& Carr, 2011). Studies have found that sexual minority women are primarily sexualized by men (Tebbe, Moradi, Connelly, Lenzen, \& Flores., 2018).

However, cyberspace is also believed to be a safe place to express one's self including minorities. As Marciano (2014) states for marginalized and stigmatized groups who face discrimination, online environments are particularly appealing because they provide a mediated experience that is easier to control and maneuver. Social media is used as platform to express Lesbians' as well as LGBTQ+ community's true selves. LGBTQ+ people use social media as a place to express themselves and consider it as a safe-space to express their identity freely. They actively voice out their idea about rights and selfexpression. As Russel (2002) said below:

The Internet has provided sexual minority with a safe place in which to explore identities, come out to one another, and tell their stories ... Such free spaces characterize the 'virtual communities' of sexual minority that have recently emerged, creating opportunities for the development of relationships and identities that are not supported in the other contexts of their lives (p. 258).

Furthermore, Fan fiction comes as an alternative way to solve the problem mentioned above faced by women (lesbians). It happens because Fan fiction is unique (Koehm, 2018). In this way, fan fiction can be a safe space for minority groups that historically have not had such a space available to them. In the fem slash fan fiction works one of the most common themes found is lesbian relationship.

The finding from the conducted interviews with fem slash fan fiction writers related to fem slash fan fiction writing as the way to express their sexuality showed varied results. The first author named DK who is 
actively writing since 2013, stated that her love firstly inspired DK as a fan of her favorite idol girl group from South Korea as the reason why she decided to start writing fan fiction. DK writes fem slash works within the fan fiction writing site. That answer is in line with the definition that said fan fiction fan fiction is the creative utilization and modification of existing popular media texts by fans who take stories, worlds, and/or characters as starting points and create their own stories based on their imagination (Reißmann, Stock, Kaiser, Isenberg, \& Nieland, 2017).

DK mostly chooses comedy, romance and drama as the themes she writes in her fem slash fiction. Furthermore, DK stated that by using fan fiction writing site as medium for writing fem slash fan fiction, DK feels she is given more space and chance to express herself in free manner (especially her sexuality and her sexual orientation). DK added that she feels safe because in the online sphere there is none of her real life family, friends, or colleagues. As cited from the interview excerpt below:

"I feel safe to write in online sphere since my family, my friends and office mates aren't there, and I can write the ideas I wanna share freely" (Interview with DK on April ,13 2021).

Thus, DK feels braver and more comfortable to express her true self (including her sexuality) through the fem slash fiction she writes. DK sometimes also uses the real-life characters within the works she produces. Meanwhile, when DK was asked about responses she got from the reader, she answered that she got support from her readers. Unlike in her real life who is still opposing and think that talking and expressing one's sexuality (including the different sexual orientation) is impolite, taboo and unacceptable since DK comes from and lives in Asian conservative family. Within online sphere, DK added that she never being discriminated by other authors nor readers. Furthermore, DK explained that the supportive readers and writing environment makes her feel comfortable, enthusiastic and enjoy to produce fem slash fan fictions as the way to express her sexuality (and her sexual orientation as well). Regarding to the erotic/ explicit sexual content within her works, DK explained since the fan fiction writing site makes her feel safe (and keep her being anonymous) DK argued that it is the shape of her maturity as woman, not a pervert thing nor glorifying pornography. As she said below:

"Writing an erotic story is different to a thing called as being pervert, it is our expression of maturity as mature woman" (Interview with DK on April,13 2021).

The next interview with author named $\mathrm{AO}$ revealed that $\mathrm{AO}$ found fan fiction writing site helped her a lot in expressing her true self and her sexuality. AO who is active in the fan fiction writing and reading since 2015. AO limited herself in writing fem slash fan fictions only. Similar to DK, AO is inspired by her favorite idol group as the inspiration in writing stories. AO explained by writing fan fiction, it made her feel free to express herself. AO feels comfortable because within online space, there is no one judge her sexuality. In fan fiction writing site, AO feels free to be herself, not wearing mask like in her real life, as she said on the interview:

"I feel the freedom, no one judge me, I can be myself and it makes me comfortable" (Interview with $\mathrm{AO}, 14$ April 2021).

In writing fan fictions, she prefers to put romance and action as the theme. Similar to DK, AO stated that online space supports her 
and no one discriminates her when she tries to express her sexuality through the works she write. AO said that within her real life, her environment is quite conservative and really praising the heteronormative values. In short she said that her environment is homophobic, that became reason why she feels more comfortable of expressing herself in online world rather than real world.

"Although US is starting to accept the homosexuality, My family is homophobic. Being Asian descent, my self is making me to be careful in managing my behavior. So I realized that I do have this intersection attributes inside me. Being Asian sometimes I experience the cat calling, I cannot imagine if I declare my sexuality in my offline, maybe I'll be cursed, bullied..I am afraid of that" (Interview with $\mathrm{AO}$, 14 April 2021).

Regarding to the explicit scenes in her works, AO stated that it is the way to enjoy life. Inserting adult scenes is not promoting the pornography, but it is a form of being expressive and loving self, as cited from the interview, "Yeah, It is one of my ways to enjoy things in life" (Interview with AO, 14 April 2021).

The last interview is with author named $\mathrm{JN}$. The interview discovered that $\mathrm{JN}$ is actively being both reader and writer in fan fiction site since 2015. JN explained that she is into fem slash and lesbian fan fiction genre. JN got the inspiration for the fan fictions' idea from her favorite artists in Korean showbiz industry. Similar to DK and AO, JN said by writing fan fictions she feels safe and free to express the thing that she tries to hide from her real life, her different sexual orientation as lesbian. In writing fem slash fan fictions, JN chooses romance, family and friendships as the main themes of her works. JN also feels comfortable and accepted in cyber space like fan fiction writing site.

"I feel safe and accepted here in the online writing platform, so I can freely share my aspiration thru my works" (Interview with JN, 15 April 2021).

Because of the sense of support and acceptance, it made $\mathrm{JN}$ feels comfortable to express herself, her sexuality and her sexual orientation as lesbian. JN considered online space as her sanctuary and safe space to express her true self, similar to DK and AO. In the cyber space like fan fiction writing site, JN got supports and rarely (almost never) got critiques. Hence, JN feels that fan fiction writing site is a very safe place to express herself, as a place for self-actualization.

In short, from the interview above, it could be concluded that the fan fiction writing sites could be a safe space for lesbians to express their sexuality. They feel free to express their ideas and aspiration as the act of showing their sexuality. It is in line with Russel (2005) and Marciano (2014) which states for marginalized and stigmatized groups who face discrimination, online environments are particularly appealing because they provide a mediated experience that is easier to control and maneuver since those interviewees are easily controlling their freedom to freely express their sexuality as lesbians in the online sphere.

\section{CONCLUSION}

Regarding to the fan fiction as the safe space to express lesbians sexuality, from the data gathered above, there are some conclusion that could be drawn. First, being lesbian in Asian American family is still considering bringing hardship and challenging for woman, especially lesbian. The intersection of being Asian American woman 
with different sexual orientation make them discriminated and receiving different treatment in real life. Second, Asian American women find that online space like fan fiction writing site is considering as a safe space to express their true-self, including their sexuality. Third, writing fem slash is considering as a way to express themselves and their sexuality (including their sexual orientation), and lastly, writing fem slash fan fictions could be used as a tool to be empowered, challenging the heteronormativity and intersectionality in patriarchal society.

\section{REFERENCES}

Alexanderson, K. (2015, 07 October). Explainer: What is fanfiction?, The conversation.

https://theconversation.com/explainerwhat-is-fanfiction-48150

Alfasi, Y. (2019). The grass is always greener on my friends' profiles: The effect of Facebook social comparison on state self-esteem and depression. Personality and Individual Differences, 147, 111117.

Aragon, A. P. (2006). Challenging lesbian norms : Intersex, transgender, intersectional, and queer perspectives. Routledge.

Bailey, J., Steeves, V., Burkell, J., \& Reagan, P. (2013). Negotiating with gender stereotypes on social networking sites: From "Bicycle Face" to Facebook. Journal of Communication Inquiry, 91112.

Black, R. W. (2005). Language, culture, and identity in online fanfiction. E-Learning, 170-184.

Black, R. W. (2009). Online fan fiction, global identities, and imagination. Research in the teaching of English, May 2009, 43(4), 397-425.
Boog, J. (2008, September 18). Mediabistro. https://web.archive.org/web/20130210 011535/http://www.mediabistro.com/g alleycat/brokeback-33percent b7743?c=rss

Boudourides, M. A., \& Drakou, a. E. (2000). GENDER@CYBERSPACE. University of Patras.

Brandes, S. B., \& Levin, D. (2014). "Like my status": Israeli teenage girls constructing their social connections on the facebook social network. Feminist Media Studies, 14, 743-758.

Bridges, S. K., Selvidge, M. M., \& Matthews, C. R. (2003). Lesbian women of color : Therapeutic issues and challenges. Journal of multicultural counseling and development, 113-130.

Burt, S. (2017, August 23). The promise and potential of fan fiction, The New Yorker. https://www.newyorker.com/books/pa ge-turner/the-promise-and-potentialof-fan-fiction

Cambridge. (2021, April 15). Cambridge online dictionary.

https://dictionary.cambridge.org/dictio nary/english/femslash

Chen, S. (2018, 01 June). China's complicated LGBT movement, The Diplomat. https://thediplomat.com/2018/06/china s-complicated-lgbt-movement/

Choy, G. (2019, March 12). This week in Asia. https://www.scmp.com/weekasia/explained/article/3001296/explain ed-gay-rights-lgbtq-and-same-sexmarriage-asia

Cochrane, K. (2016, 01 September). Why Heteronormativity is a Bad Thing, Teen Vogue.

https://www.teenvogue.com/story/hete ronormativity-gender-identity-sexualorientation

Commission, I. G. (2010). Summary report violence on the basis of SOGI against 
non heteronormative women in Asia. IGLHRC.

Commission, I. G. (2010). Violence on the basis of SOGI against non heteronormative women in Asia. IGLHRC.

Dewi, M. A. (2009). MEDIA MASSA DAN PENYEBARAN ISU PEREMPUAN. Jurnal Ilmu Komunikasi, 7(3), 228-236.

EDRI. (2019, July 17). EDRI.ORG. 17 July 2019, https://edri.org/our-work/thedigital-rights-lgbtq-technologyreinforces-societal-oppressions/

Finn, J. (2019, March 28). The denormalization of queer: LGBTQ people Not historical outcasts, Medium. https://medium.com/james-finn/thede-normalization-of-queerf2550bac0115

Fox, J., \& Ralston, R. (2016). Queer identity online: Information learning and teaching experiences of LGBTQ individuals on social media. Computers in human behavior, 635-642.

Gandhi, L. (2021, June 28). In Hollywood, Asian American Stories are rare, but Asian American LGBTQ stories are even rarer, NBC News. https://www.nbcnews.com/news/asianamerica/hollywood-asian-americanstories-are-rare-asian-american-lgbtqstories-rcna1270

Hillier, L., \& Harrison, L. (2007). Building realities less limited than their own: Young people practicing same-sex attraction on the internet. Sexualities, 10, 82-100.

internetworldstats. (2020, December 31). World Internet Stats. https://www.internetworldstats.com/st ats.htm

Janczak, M. (2017, May 31). Hawkmedia. https://hawkemedia.com/blog/socialmedia-lgbtq-community
Jenkins, H. (1992). Textual Poachers: Television Fans \& Participatory Culture. Routledge.

Jr, A. P. (2006). The Intersectional Imagination: What Do Lesbian and Gay Leaders of Color Have To Do With It? Race, Gender \& Class, 13(3/4), 218-238.

Kadem, C. (1999). The social impact of the internet on our society. https://www.math.umd.edu/ -bnk/CAR /project.htm

Klink, F. (2017, May 30). Fansplaining. https://www.fansplaining.com/articles/ towards-a-definition-of-fanfiction

Koehm, D. (2018). Revision as resistance: Fanfiction as an empowering community for female and queer fans. University of Connecticut.

Kozee., H., \& Tylka, T. (2006). A test of objectification theory with lesbian women. Psychology of women quarterly, 30(4), 348-357.

Kushnarenko, N. (2019, December 25). LGBT and feminism: Why does gender equality bother conservatives? Heinrich Böll Stiftung,

https://ua.boell.org/en/2019/12/25/lgbtand-feminism-why-does-genderequality-bother-conservatives

Kustritz, A. (2003). Slashing the romance narrative. The Journal of American Culture 26(3), 371-385.

Lexico, O. (2020, April 15). Lexico. https://www.lexico.com/definition/fems $\underline{\text { lash }}$

Li, A. (2021, January 11). Human Rights Hero: The LGBTQ Rights Movement. American Bar Association, https://www.americanbar.org/groups/c rsj/publications/human_rights_magazi ne home/civil-rights-reimaginingpolicing/human-rights-hero/

Mokhtar, M. F., Sukeri, W. A., \& Latiff, Z. A. (2019). SOCIAL MEDIA ROLES IN SPREADING LGBT MOVEMENTS IN 
MALAYSIA. Asian journal of media and communication, 77-82.

Manavis, S. (2018, November 23). NewStatesman.

https://www.newstatesman.com/cultur e/fiction/2018/11/internet-fanfictionbecoming-mainstream-after-movieharry-styles-potter-one-direction

Outlaw, M. (2016, June 20). Odyssey. https://www.theodysseyonline.com/wh y-is-fan-fiction-so-popular

Peterson-Reed, K. (2019). Fanfiction as performative criticism: Harry Potter racebending. Journal of creative writing studies, 1-15.

Prucher, J. (2007). Brave new words: The Oxford dictionary of science fiction. Oxford University Press, Inc.

Reißmann, W., Stock, M., Kaiser, S., Isenberg, V., \& Nieland, J.-U. (2017). Fan (Fiction) acting on media and the politics of appropriation. Cogitatio, 15-27.

Schorn, J. (2012). Subverting pornormativity: Feminist and queer intervention. Gender Forum, 37.

Smith, B. (2016). Intersectional discrimination and theoretical perspective. The equal rights review, Sixteen, 73-102.

Sueyoshi, A. (2016). Breathing Fire: Reembering Asian Pacific American Activism in Queer History. LGBTQ America: A theme study of lesbian, gay, bisexual, transgender, and queer history, Washington: National Park Foundation, https://www.nps.gov/subjects/lgbtqher itage/upload/lgbtqthemeasianpacific.pdf

Szymanski, D. M., Moffitt, L. B., \& Carr, E. R. (2011). Sexual objectification of women: Advances to theory and research. The counseling psychologist 39(1), 6-38.

Tsang, D.C. (2006). Slicing Silence: Asian Progressives Come Out. Asian Americans, pp. 220-239, https://escholarship.org/content/qt4c27 821c/qt4c27821c noSplash_a869c8d9b 80ec1b2224b2c7115b345a8.pdf?t $=$ n6ez $\underline{45}$

Tebbe, E., Moradi, B., Connelly, K., Lenzen, A., \& Flores., M. (2018). "I don't care about you as a person": Sexual minority women objectified. Journal of Counseling Psychology, 65(1), 1-16.

Vogel, E. A., Roberts, L. R., Okdie, B. M., \& Eckels, K. (2014 b). Social comparison, social media, and self-esteem. Psychology of popular media culture, 206-222.

Vogel, E. A., Rose, J. P., Okdie, B. M., \& Eckels, K. (2014). Social comparison, social media, and self-esteem. Psychology of popular media culture, 3(4), 206-222.

Webster, E.S. (2019, June 03). 20 Historic Moments in the Fight for LGBTQ Rights. Teen Vogue. https://www.teenvogue.com/story/lgbtequality-key-moments-timeline

Wilson-Kovacs, D. (2009). Some texts do it better: Women, sexually explicit texts and the everyday.' Mainstreaming sex: The sexualization of Western culture. IB Tauris.

Williamson, H. (2015, July 29). OpenDemocracy.

https://www.opendemocracy.net/en/50 50/misogyny-and-homophobiapatriarchy-gender-policing-and-malegaze/

Wong, B. (2020, December 17). Homophobia is not an Asian value. It's time for the East to reconnect to its own traditions of tolerance.

Time. https://time.com/5918808/homophobia -homosexuality-lgbt-asian-values/ 